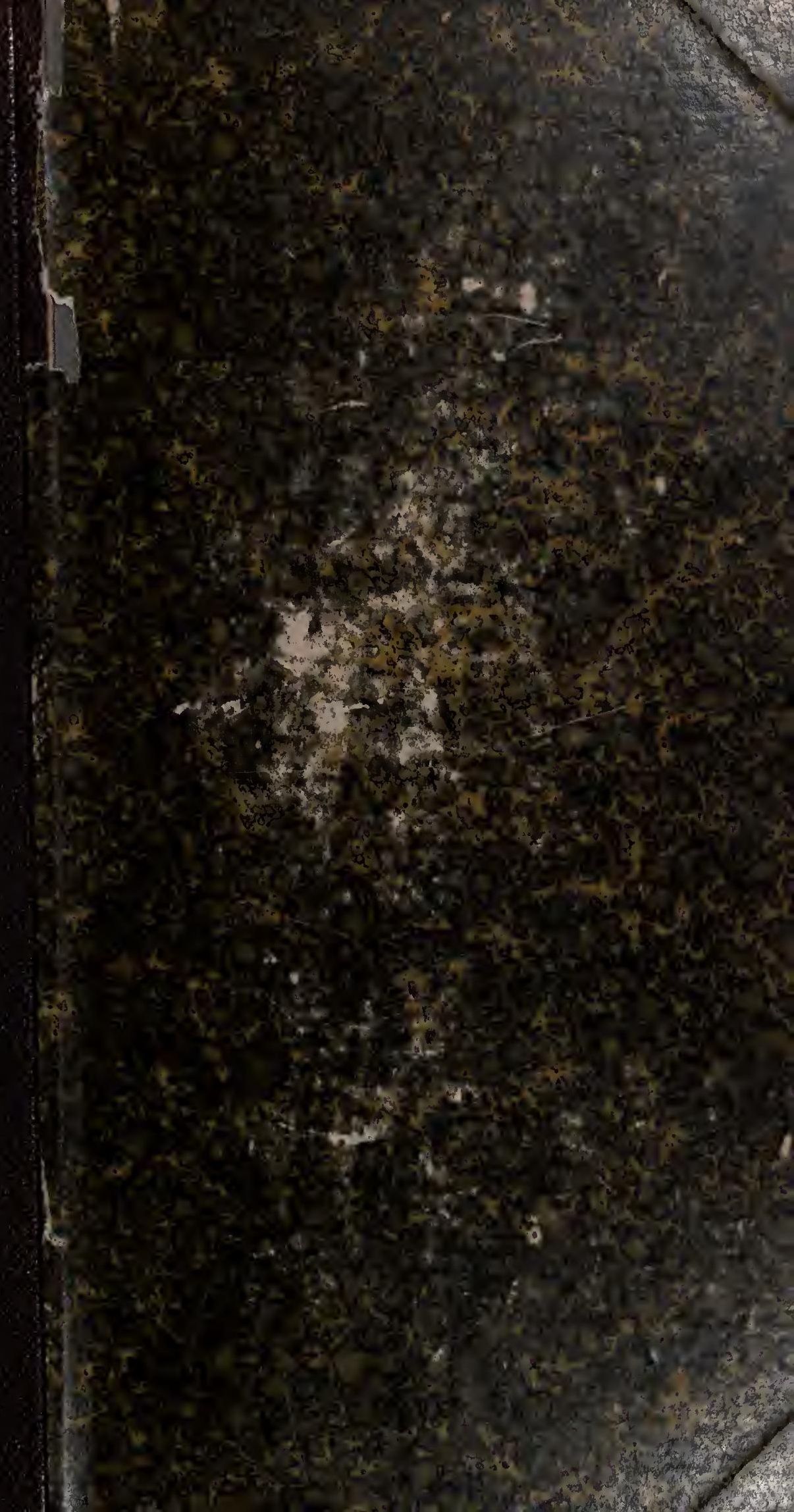




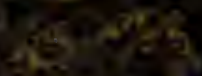

Lef

25.

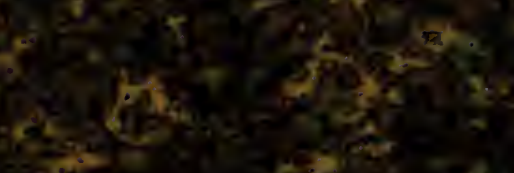

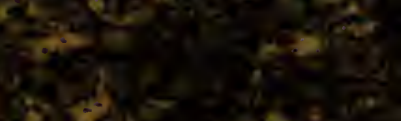

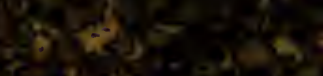

38

vis

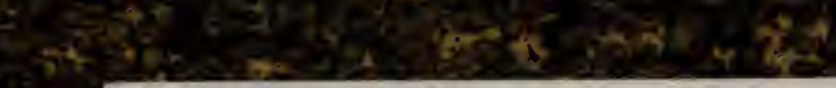

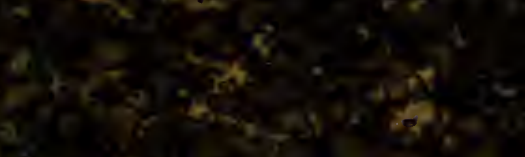
$x_{0<}, x_{2}$

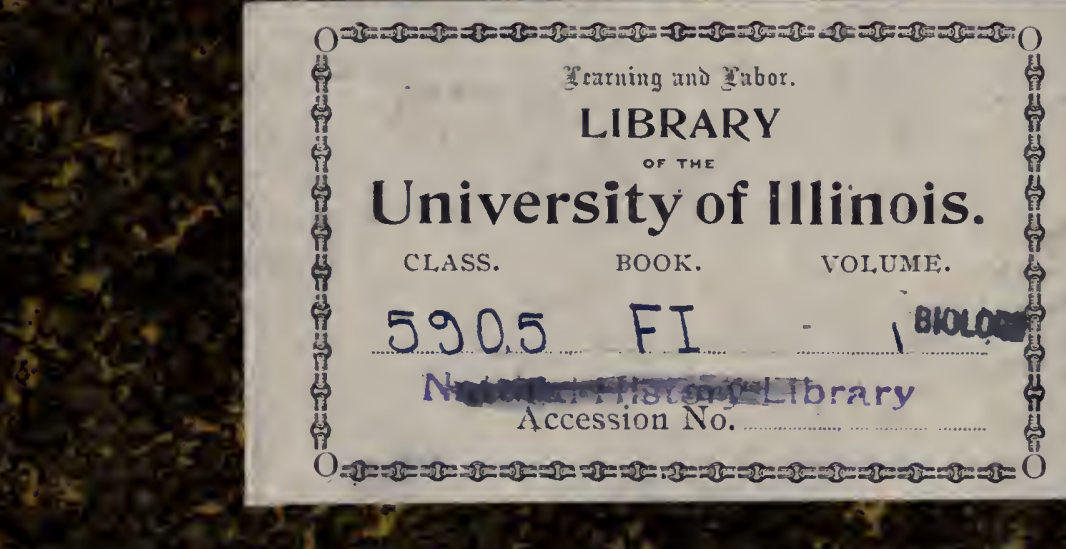

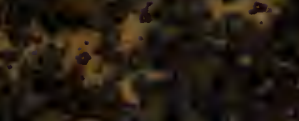

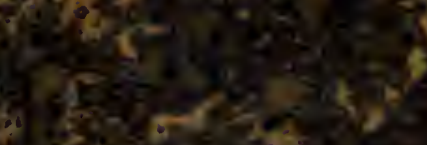


Return wis boust nator chatest Date stamped below. A books.

U. of I. Library

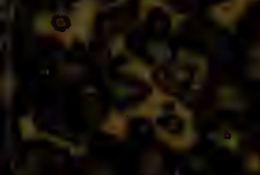

$7=$

9069

FEB 221941

FEB 51979

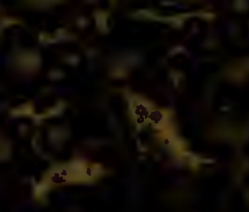

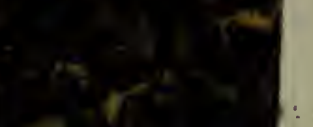

Mancar

JAN 291984

overdue 





\title{
Field Columbian Museum
}

Publication 37.

Zoological Series.

\section{DESCRIPTION}

OF

\section{APPARENTLY NEW SPECIES \\ AND SUB-SPECIES}

OF

\section{MAMMALS}

FROM

\section{OKLAHOMA TERRITORY.}

\author{
BY \\ D. G. Elliot, F.R.S.E., \\ CURATOR OF DEPARTMENT.
}

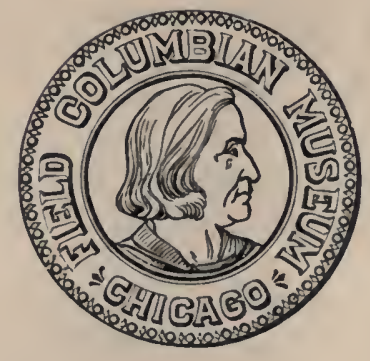

Chicago, U. S. A.

May 9, I899. 


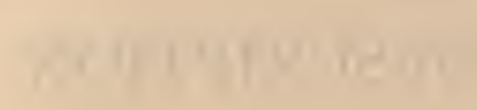

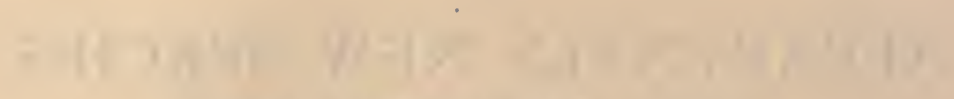

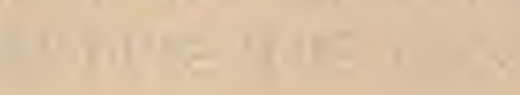

$$
\text { tix I'I' } 19
$$

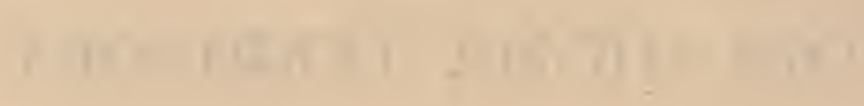


DESCRIPTIONS OF APPARENTLY NEW SPECIES AND SUBSPECIES OF MAMMALS FROM OKLAHOMA TERRITORY.

\author{
BY D. G. ELLIOT, F.R.S.E.
}

1. Neotoma macropus surberi, subsp. nov.

Type locality. Cañon three miles west of Alva, Oklahoma Territory. Adult o. Collected February 20, I 899 , by Thaddeus Surber.

Characters. Similar to $N$. macropus, and $N$. m. canescens, but darker above, with a longer tail having the upper part almost black.

Color. Entire upper parts of body, and forelegs, and flanks, iron gray, the hairs tipped with white. Top of head same color, but the cheeks a paler gray. Under parts white, hairs of chin, throat, breast and space between hind legs, white to the roots, those of remaining portion plumbeous at base. Hands and feet pure white to wrists and ankles. Tail long, above grayish black on basal third, almost pure black for remaining parts. Sides and under parts pure white. Ears slightly covered with brownish-black hairs, the bases hidden by tufts of iron-gray hairs. Whiskers long, black with a few white bristles intermingled.

Cranial characters. The skull of the present sub-species is considerably larger than that of $N$. micropus, even the female's exceeding in size that of the male of that species. The interorbital space, however, is narrower, the palate longer, as is also the upper tooth row. The nasals also are longer and broader anteriorly. Zygomatic width much greater, and the zygomatic arch more square in outline posteriorly, the process of the squamosal projecting outward and then at a right angle forward.

Measurements. Total length, $430 \mathrm{~mm}$. Tail, 197. Hind foot, 43 .

Skull. Occipito-nasal, length, $50 \mathrm{~mm}$. Basilar length of Hensel, .43. Greatest zygomatic breadth, 28. Greatest mastoid breadth, 20. Breadth across postorbital processes, Io. Least inter-orbital breadth, 6.5. Palatal length, 10. Length of nasals, 2o. Upper tooth row along alveolus, ro. Height of coronoid 
process from angle, I5. Greatest length of under jaw from outer edge of condyle to alveolus of incisors inside, 30 .

This handsome wood rat was procured by Mr. Surber in a rocky cañon a few miles from Alva in the northwestern part of Oklahoma Territory. It appears to be scarce, only three individuals having been seen, two of which were secured. But as Mr. Surber is still working in the Territory it is hoped he may obtain additional specimens. $N$. m. surberi is related to the $N$. macropus and $N$. $m$. canescens style of wood rat, but can readily be distinguished from both, by its larger size, much longer tail, and darker color. Not having any specimens of $N . m$. canescens, I sent one of my specimens to Dr. Allen and it was compared with his type, and he states that surberi is a darker gray with the upper surface of the tail much darker. His specimen was taken in May, the type of surberi in February. A point not touched upon in his letter, but which has a specific value is, in his description of canescens Dr. Allen states that the hairs on the lower surface of the body are pure white to the base. In surberi the entirely white hairs are confined to the breast, throat and space between hind legs, the remainder having plumbeous bases. The difference in the length of tail is very great. That of canescens $\delta$, presumably the type, being $135 \mathrm{~mm}$, while that of $\delta$ surberi type is $197 \mathrm{~mm}$. The tail of $q$ surberi, which is much shorter than that of the male, is yet $23 \mathrm{~mm}$. longer than the $\delta$ canescens, being $15^{8} \mathrm{~mm}$. to $135 \mathrm{~mm}$. The length of tail of $M$. macropus is about the same as that of $N$. m. canescens, seven specimens averaging about $136 \mathrm{~mm}$.

I have named this animal after Mr. Thaddeus Surber, the official collector of the Field Museum.

\section{Scalops machrinus intermedius.}

Type locality. Alva, Oklahoma Territory. Adult $\delta$. Collected February 23, I899, by Thaddeus Surber.

Characters. Similar in color to S. m. texamus Allen, but much larger, being nearly of the same size as average specimens of $S$. a. machrinus from Arkansas, and other Southwestern States, but quite differently colored from them.

Color. Entire upper parts silvery-brown, somewhat lighter than the hue exhibited by $S$. m. texanus, but in some lights this is obscured by a beautiful light purple sheen. Cheeks, chin and upper part of throat brownish-green, a color difficult to define as it is constantly changing according to the light, occasionally 
suffused with rust or orange color. Forehead with a small spot at side of nose pale pink, in some specimens orange. Breast, near the feet on front legs, and center of abdomen pale chestnut; rest of under part plumbeous, with a silvery sheen in most lights. Front feet broad and powerful, hind feet slender, flesh color. Nose prominent, extending beyond the mouth, flesh color, as is also the short tail.

Cranial characters. With $S$. m. texanus, the difference in size is so considerable that a comparison of their skulls is quite needless. Compared with that of S. a. machrinus, that of the Oklahoma animal is smaller in all its general measurements, and there are also other considerable differences. The nasals while shorter are equally as broad as in the northern form, and the maxillx are much more swollen outward anteriorly in conformity with the outward curve of the upper tooth row. The least inter-orbital width is greater than that of $S$. a. machrinus, and the brain case is narrower in the widest part for its relative length. From the hamular process of the pterygoids to the extreme point in the palatal notch the distance is greater in the new sub-species, and the palate from the notch to the alveolus of incisor inside, is shorter, but equally as broad in the widest part. The molars are as large, if not larger, than those of $S$. a. machrinus, but the premolars are smaller. The angle of the mandible in the last named form, and the coronoid process at base, are wider.

Measurements. Total length, $167 \mathrm{~mm}$. Tail, 33. Hind foot, 22. Width of hand, I8.

Skull. Occipito-nasal, length, $34 \mathrm{~mm}$. Greatest mastoid breadth, I7.5. Least inter-orbital breadth, I3. Hamular process of pterygoid to palatal notch, 6. Palatal length from notch to alveolus of incisors, inside, I4.5. Greatest breadth inside molars, 6. ; greatest outside molars, II. Greatest breadth of maxillæ, Ir.

This mole while resembling in color and the prevalence of rusty or orange hues the $S$. m. texanus is altogether too large to be identified with that sub-species. In size it is much nearer $S$. a. machrinus, but in color does not agree with it, having the general hue much too light for even the palest example of the northern sub-species that I have seen. Several specimens were obtained by Mr. Surber, all agreeing in size and color.

\section{Reithrodontomys chrysotis, sp. nov.}

Type locality. Dougherty, Oklahoma Territory. Adult $\hat{\sigma}$. Collected April I 2, r899, by Thaddeus Surber. 
Characters. Similar in color to $R$. longicaudus, but larger with longer tail, larger feet and the ears conspicuously colored inside with orange.

Color. Above with dorsal area blackish-brown interspersed with yellow hair, sides of head, body and upper part of forelegs yellowish-brown, becoming almost a golden hue above the white along the flanks. Under parts white, base of hairs plumbeous. Ears with bases concealed beneath tufts of yellowish-brown hairs. Apical portion outside covered with blackish-brown hairs; inside orange especially conspicuous on apical third. Hands and hind feet grayish-white. 'Tail rather stout, sparsely covered with hair, brownish-black above, white beneath. Whiskers long, black. On the breast are three small fulvous spots, one in the center, and one at side of each foreleg.

Cranial characters. Compared with the skull of $R$. longicaudus, that of the present species is very much larger in every way, so much superior in size as to make a detailed comparison quite needless.

Skull. Brain case very broad for its length, narrowing sharply anteriorly to the orbital constriction. Nasals very broad posteriorly, the anterior end about half as wide as the basal; Auditory bullæ large. Zygomatic arch swelling very little outwards. Occipital-nasal length, $21.5 \mathrm{~mm}$.; least orbital constriction, 3; length of nasals, 9; width at base, 3; greatest mastoid breadth, Io; zygomatic breadth, I2; length of pterygoid, 4; palate, 4; length of Hensel, I6; greatest breadth of molars outside, anteriorly, $4 \cdot 5$.

Measurements. Total length, I53 mm. Tail, 79. Hind foot, 20. Ear, I 5 .

This harvest mouse bears a general resemblance to $R$. longicaudus from California, but is readily distinguished by the larger ears and their orange or golden hue inside, by the very differently colored, and larger hands and feet, and the much stouter tail. There is no reddish fulvous visible, as serves to designate $R$. arizonensis as described by Dr. Allen, and the tail is very distinctly, not "indistinctly," bicolor.

The above-mentioned species appear to be the only ones with which $R$. chrysotis can be compared. 





$$
\begin{aligned}
& 3 x+2
\end{aligned}
$$

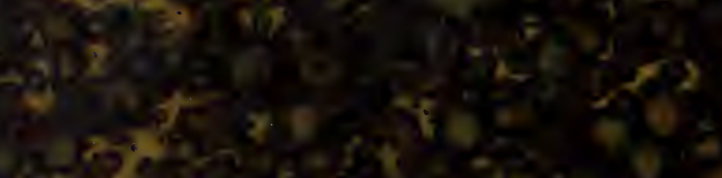

$$
\begin{aligned}
& \text { kastios }
\end{aligned}
$$

3. $x^{2}+\operatorname{sen}^{2}$

$\lambda$

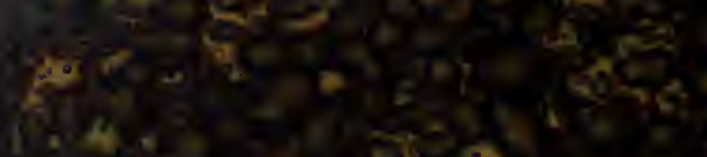

8
$8 x^{\circ}+20 \%$
(4) 3

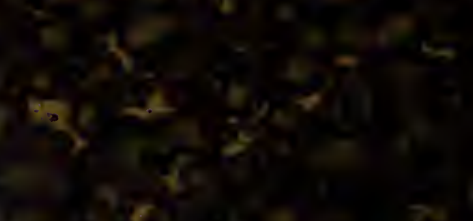
$x$
$x \rightarrow \frac{1}{4}$

itaits

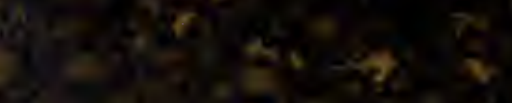

$2 x^{2}, x^{2}$

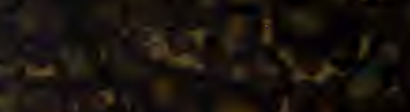

iots

$a^{2}-32$

(5) 48

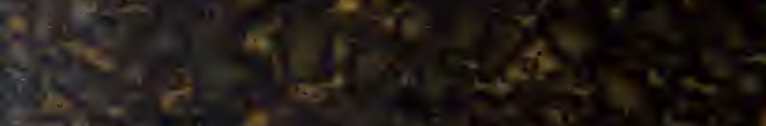

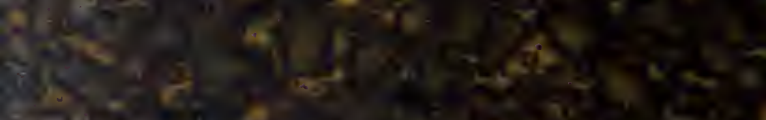

12

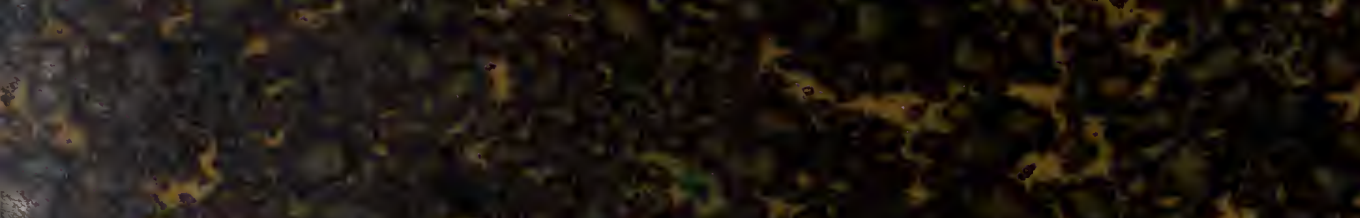

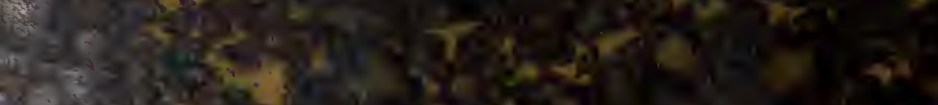




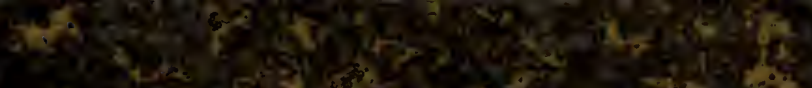

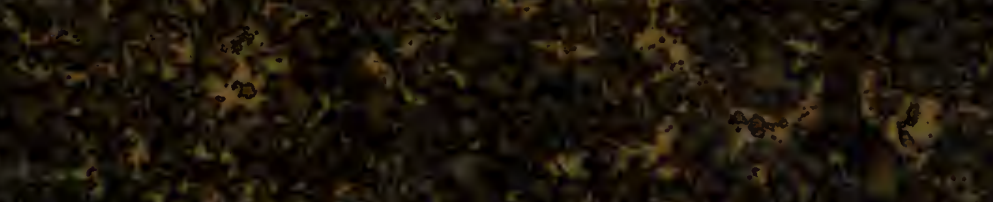

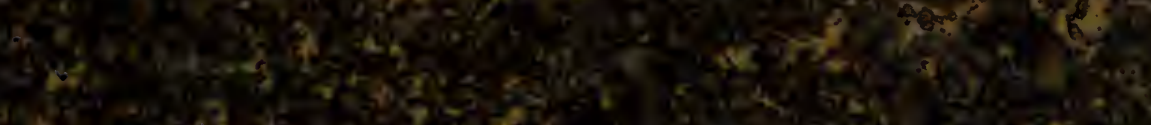

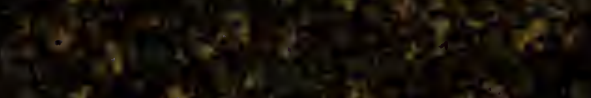

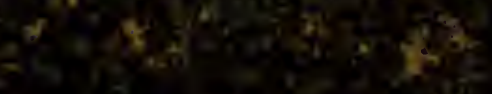

sidy

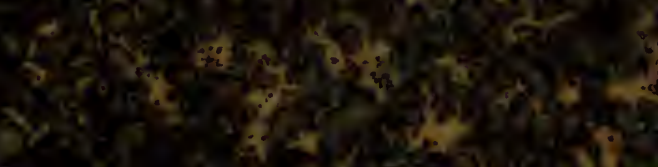

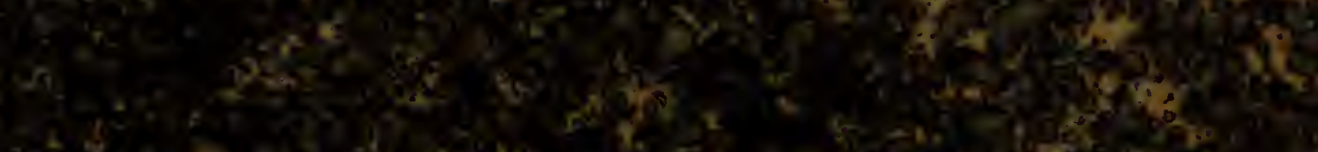

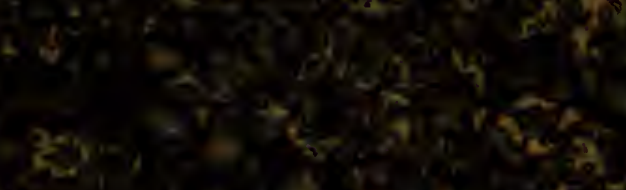

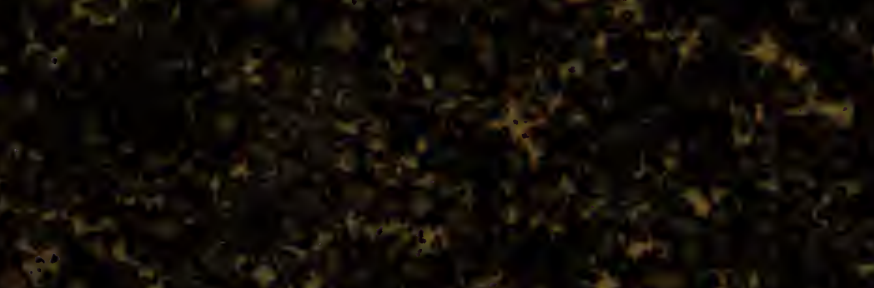

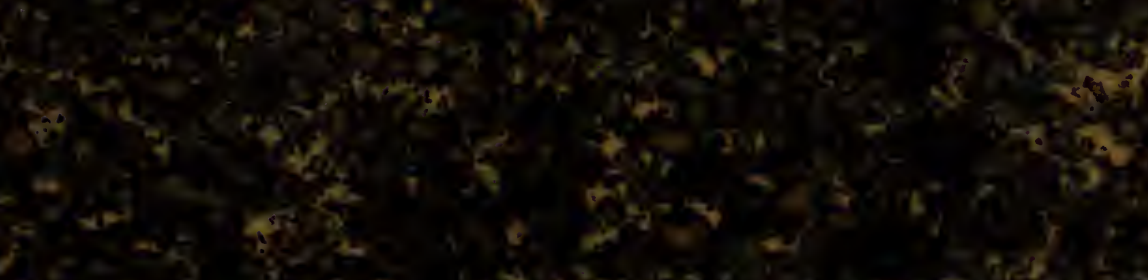

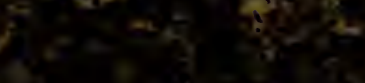

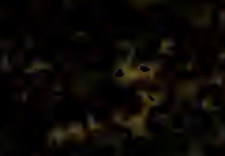

\&. $5=2$

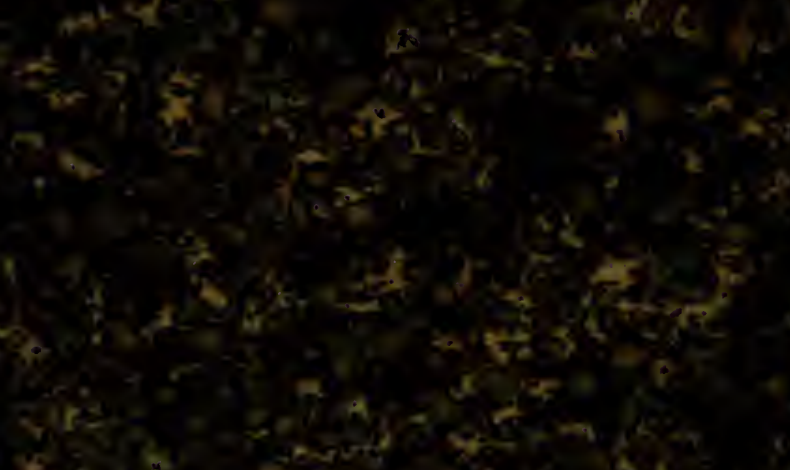

1., 0.

8,

8

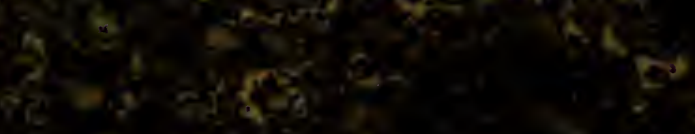
3.

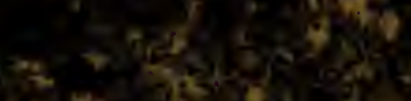
305 of

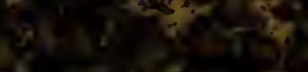

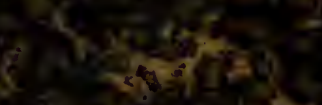
(⿻). 7 .

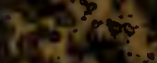

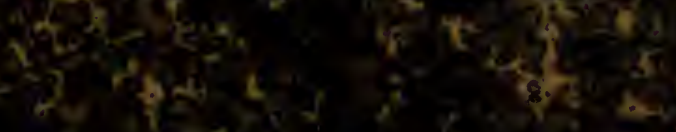
$324(5)$ 4.

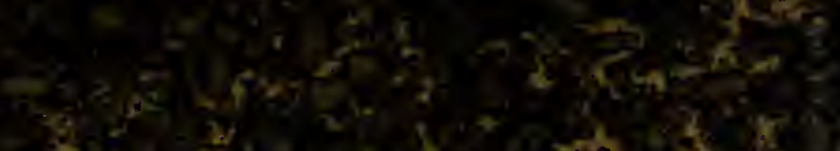

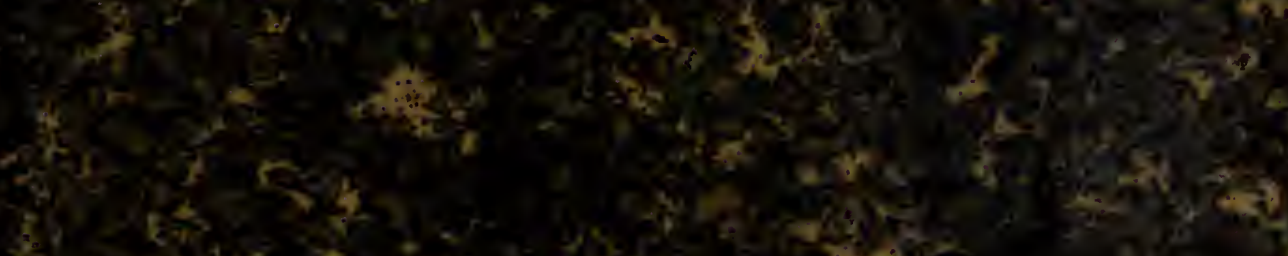

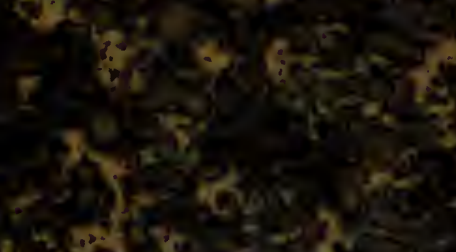


